\title{
Erratum to: Quantitative estimation of carbon removal effects due to wood utilization up to 2050 in Japan: effects from carbon storage and substitution of fossil fuels by harvested wood products
}

\author{
Yuko Tsunetsugu ${ }^{1} \cdot$ Mario Tonosaki $^{2}$
}

Published online: 24 August 2017

(C) The Japan Wood Research Society 2017

\section{Erratum to: J Wood Sci (2010) 56:339-344 DOI 10.1007/s10086-009-1107-4}

The article, Quantitative estimation of carbon removal effects due to wood utilization up to 2050 in Japan: effects from carbon storage and substitution of fossil fuels by harvested wood products, written by Yuko Tsunetsugu and Mario Tonosaki was originally published Online First without open access. After publication in volume 56, issue 4, page 339-344 the author decided to opt for Open Choice and to make the article an open access publication. Therefore, the copyright of the article has been changed to (C) The Author(s) 2017 and the article is forthwith distributed under the terms of the Creative Commons Attribution 4.0 International License (http://creativecommons. org/licenses/by/4.0/), which permits use, duplication, adaptation, distribution and reproduction in any medium or format, as long as you give appropriate credit to the original author(s) and the source, provide a link to the Creative Commons license, and indicate if changes were made.

The online version of the original article can be found under doi:10.1007/s10086-009-1107-4.

Yuko Tsunetsugu

yukot@ffpri.affrc.go.jp

1 Department of Wood Engineering, Forestry and Forest Products Research Institute, 1 Matsunosato, Tsukuba, Ibaraki 305-8687, Japan

2 Department of Wood Properties, Forestry and Forest Products Research Institute, Tsukuba, Ibaraki, Japan 